\title{
Biologic Concentration Testing in Inflammatory Bowel Disease
}

\section{Citation}

Vaughn, Byron P., William J. Sandborn, and Adam S. Cheifetz. 2015. "Biologic Concentration Testing in Inflammatory Bowel Disease." Inflammatory Bowel Diseases 21 (6): 1435-1442. doi:10.1097/MIB.0000000000000312. http://dx.doi.org/10.1097/MIB.0000000000000312.

\section{Published Version}

doi:10.1097/MIB.0000000000000312

\section{Permanent link}

http://nrs.harvard.edu/urn-3:HUL.InstRepos:17295717

\section{Terms of Use}

This article was downloaded from Harvard University's DASH repository, and is made available under the terms and conditions applicable to Other Posted Material, as set forth at http:// nrs.harvard.edu/urn-3:HUL.InstRepos:dash.current.terms-of-use\#LAA

\section{Share Your Story}

The Harvard community has made this article openly available.

Please share how this access benefits you. Submit a story.

Accessibility 


\title{
Biologic Concentration Testing in Inflammatory Bowel Disease
}

\author{
Byron P. Vaughn, MD, ${ }^{*}+$ William J. Sandborn, $M D_{1}^{*}$ and Adam S. Cheifetz, MD*
}

\begin{abstract}
Anti-TNF medications have revolutionized the care of patients with inflammatory bowel disease. However, despite an initial robust effect, loss of response is common and long-term results are disappointing. Much of this lack of durability may be due to inadequate dose optimization, and recent studies suggest a correlation between serum drug concentrations and clinical outcomes. Currently, in clinical practice, measurement of drug concentrations and antibodies to drug are typically performed only when a patient presents with active inflammatory bowel disease symptoms or during a potential immune-mediated reaction to anti-TNF ("reactive" setting). However, proactive monitoring of anti-TNF concentrations with titration to a therapeutic window (i.e., therapeutic concentration monitoring) represents a new strategy with many potential clinical benefits including prevention of immunogenicity, less need for IFX rescue therapy, and greater durability of IFX treatment. This review will cover the salient features of anti-TNF pharmacokinetics and pharmacodynamics and provide a rational approach for the use of anti-TNF concentration testing in both the reactive and proactive settings.
\end{abstract}

(Inflamm Bowel Dis 2015;21:1435-1442)

Key Words: anti-TNF, therapeutic concentration monitoring, loss of response, pharmacokinetics, pharmacodynamics, inflammatory bowel disease, Crohn's disease, ulcerative colitis, infliximab, adalimumab

A nti-tumor necrosis factor (TNF) antibodies have revolutionized the care of patients with inflammatory bowel disease (IBD). Infliximab (IFX) was the first anti-TNF approved by the U.S. Food and Drug Administration in 1998 for the treatment of Crohn's disease (CD). Since then, adalimumab (ADA) and certolizumab pegol (CTP) have been approved for use in $\mathrm{CD}$, whereas IFX, ADA, and golimumab (GOL) have been approved for the treatment of ulcerative colitis. Unfortunately, the long-term results have been somewhat disappointing with less than one-third of responders maintaining remission at 1 year. ${ }^{1}$ Much of this lack of durability may be due to inadequate dose optimization or infrequent use of combination therapy with immunosuppressive agents. Recent studies suggest a correlation between serum drug concentrations and clinical outcomes including clinical and endoscopic remission. ${ }^{2-4}$ However, in clinical practice, measurement of drug concentrations and antibody concentrations are typically performed only when a patient presents with active IBD symptoms or during a potential immune-mediated reaction to anti-TNF

Received for publication October 10, 2014; Accepted November 14, 2014.

From the *Center for Inflammatory Bowel Diseases, Division of Gastroenterology, Beth-Israel Deaconess Medical Center, Harvard Medical School, Boston, Massachusetts; ${ }^{\dagger}$ Division of Gastroenterology, Hepatology and Nutrition, University of Minnesota, Minneapolis, Minnesota; and Division of Gastroenterology, University of California San Diego, San Diego, California.

W. J. Sandborn has consulted for Prometheus and Janssen and has research support from Janssen. A. S. Cheifetz has consulted for or participated in advisory boards for Prometheus, Janssen, Abbvie, Takeda and research support from Pfizer. The remaining author has no conflicts of interest to disclose.

Reprints: Byron P. Vaughn, MD, 420 Delaware Street SE, MMC 36, Minneapolis, MN 55455 (e-mail: bvaughn@umn.edu).

Copyright (C) 2015 Crohn's \& Colitis Foundation of America, Inc.

DOI 10.1097/MIB.0000000000000312

Published online 14 January 2015. ("reactive" setting). ${ }^{5}$ Recently, preliminary data on the "proactive" measurement of IFX concentrations during routine therapy have suggested that this strategy might lead to superior clinical outcomes, including less need for IFX rescue therapy and greater durability of IFX treatment. ${ }^{6,7}$

The process of therapeutic concentration monitoring (TCM) is the measurement of serum trough concentrations with dosing titration to achieve concentrations within a prespecified therapeutic range. Although commonly performed for other medications, such as cyclosporine, tacrolimus, and certain antibiotics, ${ }^{8-10} \mathrm{TCM}$ is not currently used for biologic agents. This review will outline the relevant pharmacokinetics and pharmacodynamics of antiTNFs and discuss the potential beneficial role the expanded use of TCM for anti-TNF therapy in IBD.

\section{PHARMACOKINETICS OF ANTI-TNF ANTIBODIES}

\section{Absorption and Clearance}

Pharmacokinetics is the study of the absorption, distribution, and elimination of a given medication. ${ }^{11}$ The goal of pharmacokinetics is to identify drug dosing regimen that results in a safe and effective drug concentration in a given patient. Understanding pharmacokinetic principles of anti-TNF agents are essential for optimal dosing and efficacy. Pharmacokinetics varies between anti-TNFs based on drug makeup, route of administration, degradation, and elimination. IFX is infused intravenously, which allows a large bolus of drug to enter the system at once through the venous blood, followed by direct diffusion into the tissue resulting in a high peak concentration immediately after the infusion, which tends to be reproducible between individuals. ${ }^{12-14}$ ADA, CTP, and GOL are injected subcutaneously (SC), which 
tends to have a more variable absorption, likely related to lymphatic absorption of drug before reaching the venous system. ${ }^{12}$ Thus, drugs administered SC take longer to reach the systemic circulation, with peak drug concentrations not occurring until up to 10 days after injection. The bioavailability of SC administration also varies greatly, ranging from $50 \%$ to $100 \%{ }^{12}$

Degradation and elimination of monoclonal antibodies, including IFX, ADA, and GOL is primarily regulated by the reticuloendothelial system. ${ }^{15}$ IgG elimination (and thus anti-TNF elimination) occurs primarily via uptake into a cell through receptor-mediated endocytosis and subsequent intracellular catabolism. Various endogenous mechanisms are in place to protect human antibodies from being metabolized. ${ }^{16}$ These mechanisms likely contribute to the variation in half-life between murine $\mathrm{IgG}$ (1-2 d), murine/human chimeric antibodies (10-14 d), and fully humanized antibodies $(10-20 \mathrm{~d}) .{ }^{17}$ An important clinical note is that at times of inflammation, these pathways can be saturated, thus decreasing the half-life of all antibodies (including anti-TNF antibodies) in circulation.

In addition to humanizing anti-TNFs, they can be modified to have the Fc portion removed and replaced with a polyethelene glycol chain, such as CTP. This extends the half-life of the molecule by 2 weeks in the plasma and decreases the probability of antidrug antibody development but does not eliminate it. ${ }^{18,19}$ Additional factors aside from the makeup of the drug also have a significant impact on clearance. In a pharmacokinetic analysis of ACT1 and ACT2, body weight, sex, albumin, and ATI status were independently associated with serum IFX concentration. ${ }^{14}$ Genetics and volume of distribution likely account for at least some of the gender and weight differences. Low albumin has been consistently associated with low IFX concentrations and increased clearance $^{14,20}$ and may be related to inflammation and increased protein loss, including IFX, in the stool of patients with active IBD. $^{21}$ When present, antidrug antibodies (immunogenicity) become a dominant factor affecting anti-TNF medications as it increases the clearance through phagocytosis. ${ }^{12,15}$ Although many factors affecting clearance of an anti-TNF are fixed (e.g., route of administration, gender, genetic predisposition), preventing antibodies to anti-TNFs represents one of the key potential benefits of TCM.

\section{Immunogenicity}

The immunogenicity of anti-TNFs is complex and affected by multiple drug, provider, and patient factors. ${ }^{22}$ Anti-TNFs with a murine component (IFX) is inherently more immunogenic that fully humanized antibodies. ${ }^{23}$ The route of administration is also important as SC administration exposes the drug to more antigenic cells, such as dendritic cells. ${ }^{24}$ Storage elements, such as temperature, light exposure, and agitation can lead to protein aggregation and increased immunogenicity. ${ }^{22}$ Certain provider factors, such as induction dosing, scheduled dosing, and the coadministration of immunosuppressives are protective against the development of antidrug antibodies. ${ }^{25,26}$ Patient factors, such as gender and weight, described above can also affect drug clearance, concentration, and antibody development. The underlying genetic makeup of an individual also determines one's predisposition to antidrug antibody formation. In one study of patients on ADA, IL10 polymorphisms were associated with increased antibody formation. ${ }^{27}$ This may account for the observation that patients who develop antibodies to IFX are prone to develop antibodies to ADA. ${ }^{28}$ Thus, despite optimizing all other factors, some patients may still be inherently at risk for developing antidrug antibodies.

The development of antibodies to anti-TNF medications has the potential to lead to at least 3 clinically relevant scenarios: increased clearance, infusion reactions, or induction of autoimmunity. ${ }^{29}$ Antibodies to biologics are typically IgG antibodies. ${ }^{12}$ Increased binding of antibodies to a biologic will increase clearance through phagocytosis. ${ }^{12,15}$ Development of antibodies to anti-TNF antibodies has been associated with secondary loss of response and infusion reactions. ${ }^{26,30-33}$ However, the development of low-level antibodies seems to present a different scenario than high-titer antibodies. ${ }^{34}$ Low-titer ATI are less likely to lead to infusion reactions or cessation of IFX therapy compared with patients with high-titer ATI. ${ }^{35}$ There remains controversy regarding antibody status, especially in the setting of both detectable serum drug concentration and detectable antibody to drug concentration. However, the prevailing notion is that even low-level immunogenicity leads to increased clearance and increases the probability of infusion reactions. ${ }^{36}$

Based on these pharmacokinetic principles, variations of serum drug concentration should be expected to occur both between individuals and within an individual over time. Before reviewing the clinical effect of serum drug concentrations (i.e., the pharmacodynamics), we will first review the types of testing available for serum monoclonal antibody concentration.

\section{TYPES OF CONCENTRATION TESTING}

There is no standardized test for measuring a monoclonal antibody or antidrug antibodies. Various laboratories use different assays, which ultimately limit the ability to directly compare concentrations between assays. The bulk of antibody testing is currently performed for IFX, although recently, testing for ADA concentrations and antibodies has become commercially available as well.

\section{Infliximab}

There are 3 common methods to measure IFX serum concentration and antibody status: enzyme-linked immunosorbent assay (ELISA), radio-immunoassay (RIA), and fluid phase mobility shift assay. Bridging ELISA testing is probably the most common form of testing. The lower limit of detection for this test ranges based on the assay from 1.4 to $0.002 \mu \mathrm{g} / \mathrm{mL}^{26,37}$ This method can also be used to detect ATI; however, the presence of IFX in the serum will interfere with ATI testing. Thus, ATI is only measurable when serum IFX is undetectable. ${ }^{26,38}$ RIA is not commonly used in the United States but is used in 
laboratories in Denmark and the Netherlands. ${ }^{39}$ RIA is a sensitive, specific, and inexpensive form of testing that is similar to ELISA but uses a radioactive reagent, thus limiting its practical use. ${ }^{40}$ Similar to ELISA, RIA cannot detect ATI in the presence of IFX.

Prometheus Laboratories (San Diego, CA) has commercialized a fluid phase mobility shift assay. The mobility shift assay uses high-performance liquid chromatography to measure both IFX concentration and ATI. ${ }^{38}$ This test was developed as an alternative to ELISA and RIA, neither of which can measure ATI when IFX is detectable in the serum. The ability to detect ATI in the presence of serum IFX is an advantage; however, the cost of the assay may limit its widespread use. More recently, Labcorp developed an ECLIA (electrochemiluminescence immunoassay), which has a lower limit of detection than ELISA $(0.4 \mu \mathrm{g} / \mathrm{mL})$ and can also measure ATI in the presence of serum IFX. However, no clinical validation data are available with this assay, and so its current use in clinical practice is uncertain.

\section{ADA and CTP}

Similar to IFX, ADA is most commonly tested by ELISA as described above. There are 2 tests for ADA that are commercially available in the U.S. Labcorp developed ECLIA testing for ADA and antibody to ADA concentration (AAA), and Prometheus laboratories has a fluid phase mobility shift assay to detect both ADA concentration and AAA. Similar to the situation described above for IFX, no clinical validation data are available with the Labcorp assay, and so its current use in clinical practice is limited. CTP concentration can be measured through ELISA for research purposes; however, as of the writing of this review, there are no commercial tests available.

\section{PHARMACODYNAMICS OF ANTI-TNF: CONCENTRATION AND OUTCOME}

Pharmacodynamics is the quantitative effect of a drug on the body. ${ }^{11}$ This includes both the desired therapeutic effect and unwanted toxic effects. Ideally, a drug is dosed to maximize the clinical effect in a patient without any toxic effects. This dose range is sometimes referred to as a therapeutic window. The therapeutic window for anti-TNF medications has not been defined; however, based on the current evidence, it is possible to draw reasonable conclusions regarding the trough concentration.

Numerous studies have attempted to determine the minimally effective dose and are summarized in Table $1 .{ }^{41-51}$ Mechanistically, maintaining a detectable trough concentration is logical as the goal of maintenance drug therapy is to have continuous suppression of disease. Additionally, continuously detectable trough concentrations likely decrease immunogenicity. ${ }^{26,32,33}$ Clinically, trough concentrations (typically IFX $>3 \mu \mathrm{g} / \mathrm{mL}$ ) have been associated with improved outcomes, including clinical remission and mucosal healing. ${ }^{41,47}$ Based on these studies, it seems reasonable to focus on titrating an anti-TNF to the minimal effective concentration rather than a standard weight-based or one size fits all dosing. This allows for both dose escalation of an anti-TNF, which will improve clinical response and likely decrease antibody formation and dose de-escalation to avoid unnecessarily high drug concentrations and a potentially increased risk of adverse events. Although most of the data focus on IFX, the principles of targeting to a therapeutic window can likely be applied across all anti-TNF, but the ideal upper and lower trough concentration will need to be defined for each anti-TNF individually.

\section{ANTI-TNF CONCENTRATION AND ANTIBODY TESTING IN PRACTICE}

\section{Reactive Testing}

Currently, drug concentration and antibody measurement is typically done when a patient is symptomatic, i.e., reactive testing. This is most commonly done for IFX, although testing for ADA is now available. Symptoms that prompt reactive testing typically include recurrence of gastrointestinal symptoms or concern for an antibody-mediated side effect. Reactive testing provides several potential benefits over empiric dose escalation including appropriately directing care. IFX concentration and ATI measurement can identify patients in whom empiric dose escalation would not be appropriate, such as those with a therapeutic IFX concentration or those with high-titer ATI. Using a decision analysis model, a recent study demonstrated similar outcomes between empiric dose escalation and reactive testing with regards to clinical remission and improvement, but at a lower cost for reactive concentration testing. ${ }^{52}$ This algorithm was subsequently confirmed by a randomized controlled trial. ${ }^{53}$ Additionally, a recently prospective study demonstrated that two-thirds of patients with low ADA trough concentrations $(<4.9 \mu \mathrm{g} / \mathrm{mL})$ and undetectable antidrug antibodies $(<10 \mathrm{ng} / \mathrm{mL})$ had a clinical response to $\mathrm{ADA}$ dose optimization, whereas only $12 \%$ of patients with detectable antidrug antibodies had clinical improvement after empiric dose escalation. ${ }^{51}$ This later group responded well when transitioned to IFX. Additionally, only one-third of patients with adequate ADA trough concentrations $(>4.9 \mu \mathrm{g} / \mathrm{mL})$ responded to weekly ADA and even fewer responded when transitioned to IFX.

Empiric dose escalation for disease recurrence in a patient who has either high antidrug antibody or therapeutic anti-TNF concentrations is unlikely to provide any benefit and may expose them to harm from high doses of the drug or antibody-mediated adverse events. Conversely, correctly identifying those patients with low or undetectable IFX concentration allows directed therapy to those patients who are likely to benefit from it. Knowing the drug concentration and antibody status allows for appropriate titration of an anti-TNF or changing therapy to a new anti-TNF or new class, thus sparing unnecessary use of a drug. Reactive testing is an excellent example of personalized medicine and should routinely be performed when there is a concern for loss of response or antibodymediated reaction to an anti-TNF. A treatment algorithm for using reactive testing to IFX is shown in Figure 1. 
TABLE 1. Summary of Trials Associating Anti-TNF Drug Concentration to Clinical Outcomes

\begin{tabular}{|c|c|c|c|c|}
\hline Disease & Drug & Concentration & Clinical Outcome & Notes \\
\hline $\mathrm{CD}^{41}$ & IFX & Detectable & $\begin{array}{l}\text { Clinical remission, CRP, endoscopic } \\
\text { remission }\end{array}$ & $\begin{array}{l}\text { Trough assessed after } 1 \text { yr (range, after 6-37 } \\
\text { infusion) }\end{array}$ \\
\hline $\mathrm{CD}^{43}$ & IFX & $>3$ & Sustained response & Week 14 or 24 trough \\
\hline $\mathrm{CD}^{44}$ & IFX & $>5.6$ & Reduced CRP & \\
\hline $\mathrm{UC}^{47}$ & IFX & Detectable & $\begin{array}{l}\text { Higher rates of remission, endoscopic } \\
\text { improvement }\end{array}$ & $\begin{array}{l}\text { Undetectable serum IFX associated with } \\
\text { colectomy }\end{array}$ \\
\hline $\mathrm{CD} / \mathrm{UC}^{48}$ & IXF & $>3.8$ & $\begin{array}{l}\text { Failed to respond to increase in IFX or } \\
\text { change to another anti-TNF }\end{array}$ & $\begin{array}{l}\text { Population was patients } \\
\text { with LOR }\end{array}$ \\
\hline $\mathrm{CD} / \mathrm{UC}^{50}$ & $\mathrm{ADA}$ & $>4.9$ & Mucosal healing & $\begin{array}{l}\text { Higher trough concentrations associated with } \\
\text { clinical remission and mucosal healing }\end{array}$ \\
\hline $\mathrm{UC}^{52}$ & $\mathrm{ADA}$ & $>4.58 \mu \mathrm{g} / \mathrm{mL}$ & Week 12 clinical response & $\begin{array}{l}\text { Week } 2-4 \text { concentration predicts } \\
\text { week } 12 \text { response }\end{array}$ \\
\hline $\mathrm{CD}^{49}$ & СТP & $\begin{array}{l}\text { Higher quartile (mean value for } \\
\text { highest quartile: } 30.1 \mu \mathrm{g} / \mathrm{mL} \text { ) }\end{array}$ & $\begin{array}{l}\text { Endoscopic and clinical response } \\
\text { and remission }\end{array}$ & \\
\hline
\end{tabular}

UC, ulcerative colitis; TNF, tumor necrosis factor.

\section{Proactive Testing}

Although reactive testing seems superior to empiric dose escalation, both strategies are designed to manage patients who are already symptomatic and failing treatment. A more optimal approach would allow optimization of IFX dosing from the outset to help minimize or avoid the loss of response and antibodymediated reactions. Proactive monitoring of IFX concentrations with dose optimization offers the potential for such an approach. Although proactive TCM of anti-TNFs is not currently the standard of care, recent evidence suggests that routine monitoring of IFX trough concentrations with dosing to a therapeutic window may be a more optimal way forward.

The TAXIT trial (Trough Level Adapted Treatment) was a randomized controlled trial of 251 patients that dose optimized all patients into a therapeutic window and then compared drug concentration dosing versus clinically based dosing for IFX maintenance therapy. ${ }^{6}$ Before randomization, all patients in stable clinical response underwent a dose optimization phase where IFX was titrated to a trough concentration of 3-7 $\mu \mathrm{L} / \mathrm{mL}$. Interestingly, when initially tested, only $44 \%$ of patients in stable clinical response were in the defined therapeutic window. Twenty-six percent had a trough greater than $7 \mu \mathrm{g} / \mathrm{mL}, 21 \%$ had a detectable trough but at less than $3 \mu \mathrm{g} / \mathrm{mL}$, whereas $9 \%$ had concentrations that were undetectable. After the optimization phase, among patients who underwent dose escalation for a low trough, a significantly higher proportion of patients with $\mathrm{CD}$ went into clinical remission (88\% versus $64 \%$ preoptimization, $P=0.02$ ). There was a trend for improvement with dose escalation in patients with ulcerative colitis, but this did not reach statistical significance. Additionally, dose reduction in the optimization phase did not have any effect on remission rates for either CD or ulcerative colitis. After achieving an adequate trough concentration, patients were randomized to dosing based on IFX trough concentration or based on symptoms and C-reactive protein. The primary endpoint of the study, clinical remission at 1 year, was similar in both groups (69.1 and 71.7 for clinically based and trough concentration-based groups, respectively, $P=0.77$ ). However, $17.3 \%$ of patients who had clinically based dosing required rescue therapy at the end of the study period versus $5.5 \%$ of the group dosed by trough concentration. Based on the results of the optimization phase and the secondary endpoints, the authors recommended dose optimization to 3-7 $\mu \mathrm{g} / \mathrm{mL}$ with re-evaluation of IFX concentration after 6 months.

Our own work has demonstrated a long-term benefit in IFX trough concentration monitoring and dose optimization with the greatest benefit for those who achieved an IFX trough concentration of at least $5 \mu \mathrm{g} / \mathrm{mL}$ (Fig. 2). ${ }^{7}$ We analyzed a retrospective cohort that underwent proactive TCM and compared them with similar IBD controls that were treated with standard of care (i.e., reactive testing or empiric dose escalation if needed). In our 


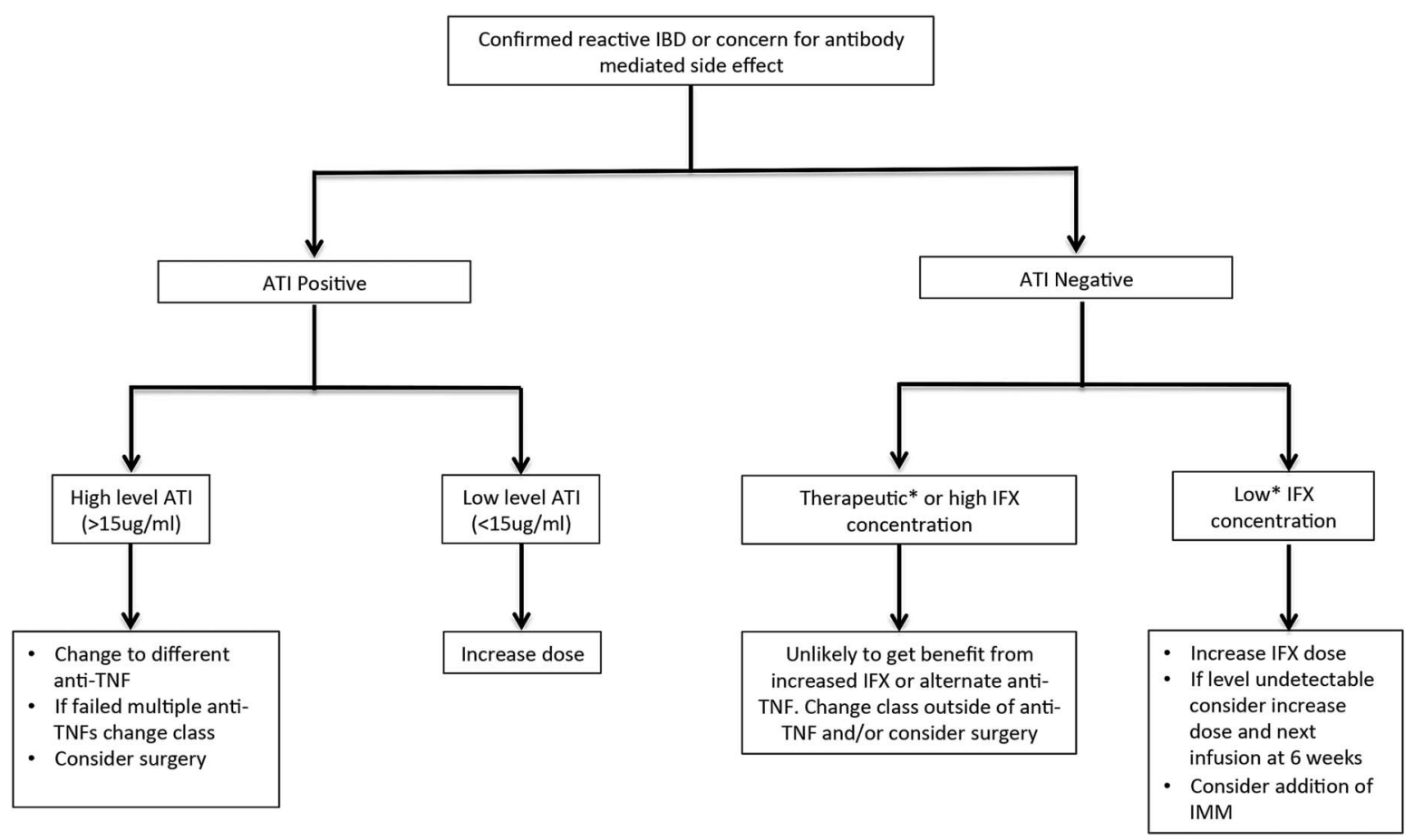

FIGURE 1. Clinical algorithm for using reactive IFX concentration and antibody status to guide therapy decisions. * Exact upper and lower limit are unknown. The authors suggest a therapeutic concentration to be 5 to $10 \mu \mathrm{g} / \mathrm{mL}$, whereas a low concentration is $<5 \mu \mathrm{g} / \mathrm{mL}$. IMM: Immunomodulator.

cohort, we defined a therapeutic window as 5 to $10 \mu \mathrm{g} / \mathrm{mL}$ based on institutional experience dosing IFX. Using this definition, only $29 \%$ of patients had a therapeutic trough concentration on initial testing, whereas $48 \%$ measured less than $5 \mu \mathrm{g} / \mathrm{mL}$ including $15 \%$ with undetectable concentrations. We found that patients who had proactive testing stopped IFX less frequently (10\% versus $31 \%$, $P=0.009)$ and remained on IFX for a longer duration (log rank test $P=0.0006)$. No patients in the proactively monitored group developed acute infusion reactions or disease recurrence, while those were the 2 main reasons for stopping IFX treatment in the standard of care group. Proactive testing resulted in only minor dose changes to achieve these benefits. The median dose escalation required in the setting of proactive monitoring was $100 \mathrm{mg}$ of IFX (range, 50-250 mg). These early observations suggest
A

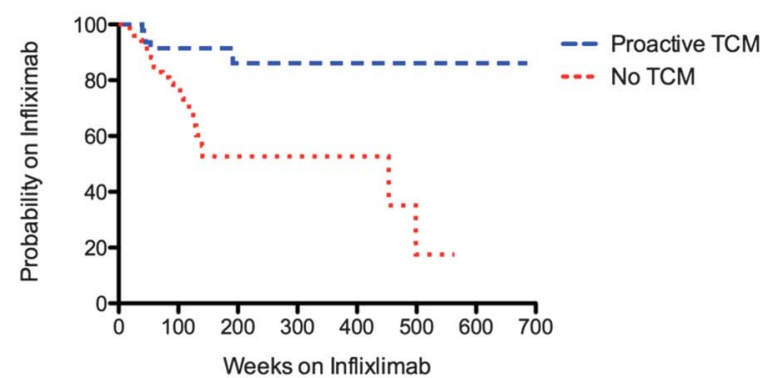

\section{Number at risk}

$\begin{array}{llllllll}\text { Proactice TCM } & 48 & 34 & 16 & 10 & 5 & 4 & 2\end{array}$

$\begin{array}{lllllll}\text { No TCM } & 77 & 29 & 10 & 5 & 4 & 2\end{array}$
B

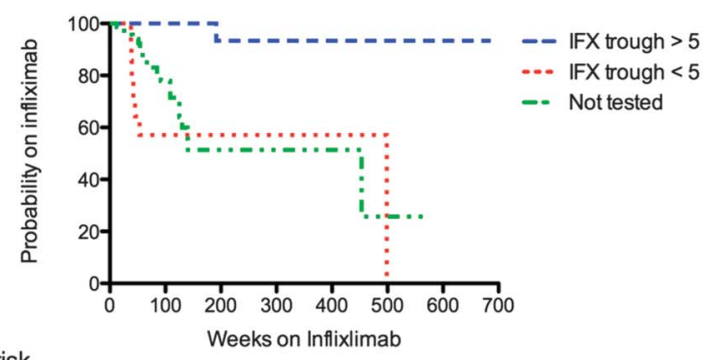

Number at risk

$\begin{array}{llllllll}\mid \mathrm{FX}>5 & 37 & 29 & 14 & 9 & 4 & 4 & 2 \\ \mathrm{IFX}<5 & 15 & 8 & 5 & 3 & 3 & & \\ \text { IFX not tested } & 73 & 27 & 8 & 4 & 3 & 2 & 1\end{array}$

FIGURE 2. A, Probability of continuing on IFX among patients who had proactive TCM of IFX through trough concentration monitoring versus control group of patients treated with standard of care ( $\mathrm{HR}, 0.3 ; 95 \% \mathrm{Cl}, 0.1-0.6$; log rank test; $P=0.0006)$. B, Probability of continuing IFX based on trough concentration. Log rank test for IFX trough $\geq 5 \mu \mathrm{g} / \mathrm{mL}$ (at any point in therapy) versus never achieving an IFX trough $<5 \mathrm{mg} / \mathrm{mL}, P<$ 0.0001 (HR: $0.03 ; 95 \% \mathrm{Cl}, 0.001-0.1$ ). Log rank test for IFX trough $\geq 5 \mu \mathrm{g} / \mathrm{mL}$ versus no trough testing, $P<0.0001$ (HR: $0.2 ; 95 \% \mathrm{Cl}$. 0.07-0.4). Log rank test for IFX trough $<5 \mu \mathrm{g} / \mathrm{mL}$ (at any point in therapy) versus no trough testing, $P=0.6$ (HR: $1.3 ; 95 \% \mathrm{Cl}, 0.5-3.3$ ). Adapted from Vaughn et al. ${ }^{7}$ Adaptations are themselves works protected by copyright. So in order to publish this adaptation, authorization must be obtained both from the owner of the copyright in the original work and from the owner of copyright in the translation or adaptation." 


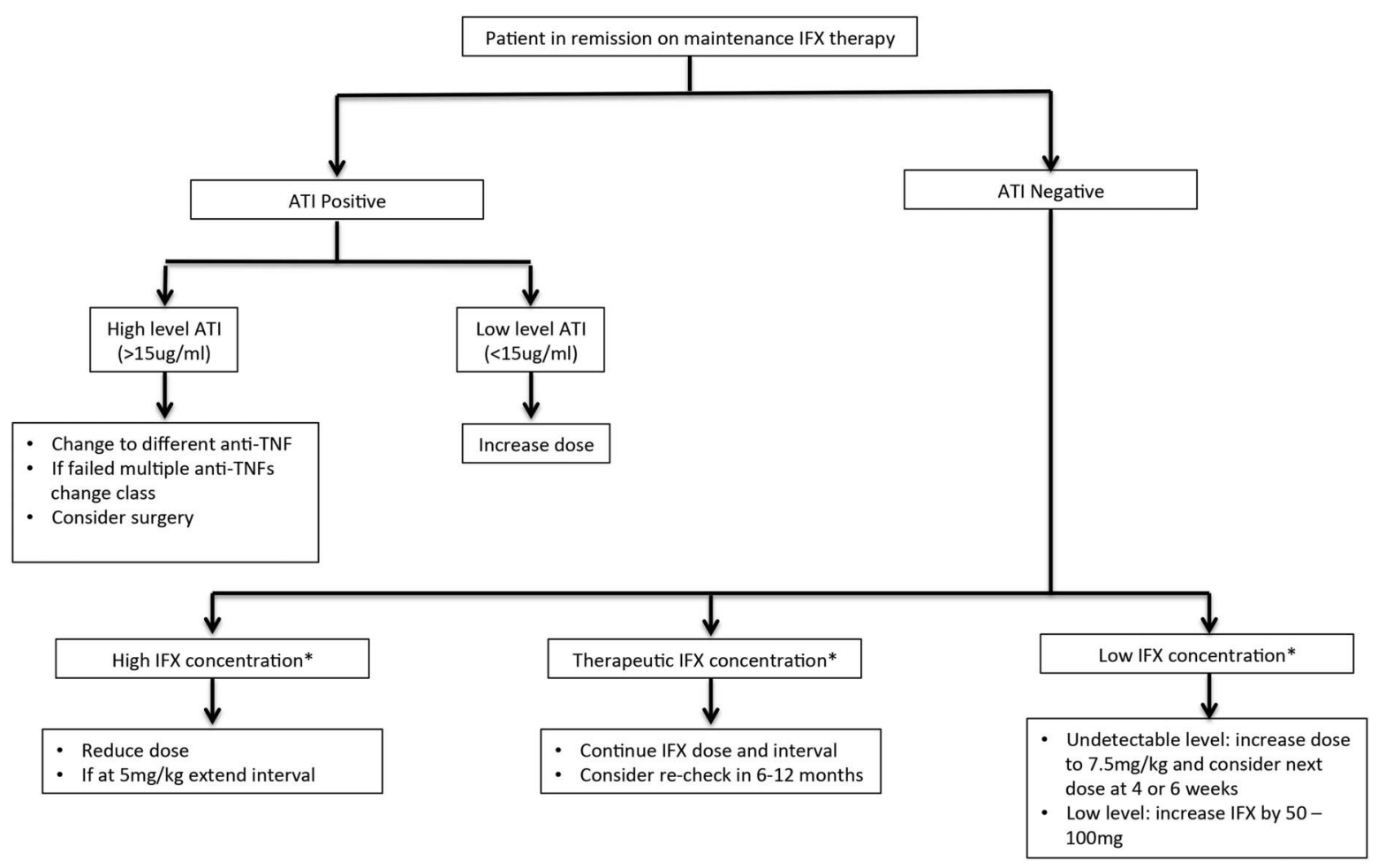

FIGURE 3. Clinical algorithm for using proactive TCM of IFX trough concentrations for dosing and management of IFX. *High, low, and therapeutic concentrations are not exactly known. The authors suggest that $>10 \mu \mathrm{g} / \mathrm{mL}$ is high, whereas less than $5 \mu \mathrm{g} / \mathrm{mL}$ is low.

a strong benefit to proactive TCM of IFX, which could have a significant impact on the duration of IFX maintenance therapy. A proposed algorithm for using proactive TCM for IFX is shown in Figure 3.

\section{Optimized Monotherapy of Anti-TNFs}

Current evidence suggests that combination of an anti-TNF with an immunomodulator is the most efficacious treatment for new onset IBD. ${ }^{2,54}$ Interestingly, in both ACCENT I and SONIC, patients who had beneficial clinical outcomes on combination therapy had a higher median IFX trough concentration. ${ }^{2,25,42}$ Thus, an important benefit of combination therapy may be in achieving a higher IFX concentration and preventing antibody formation. ${ }^{55}$ It is possible that this effect may be achievable with just titration of IFX as monotherapy without the need for combination therapy. In our own cohort, we found that the majority of patients who had proactive TCM of IFX were on monotherapy with IFX or could de-escalate from combination therapy to monotherapy with IFX. ${ }^{7}$ The 31 patients on monotherapy who were optimized (defined by achieving a trough concentration of $>3$ $\mu \mathrm{g} / \mathrm{mL}$ ) had an excellent clinical course with no need to stop IFX monotherapy over the course of the study (median of $175 \mathrm{wk}$ ). If these were confirmed prospectively, it is likely that optimized monotherapy with anti-TNF would be a preferable strategy to patients (due to a decreased risk of adverse events related to combination therapy). However, the cost-effectiveness of this approach is unknown.
One of the main issues regarding proactive TCM for antiTNF is cost. There is both the cost of the test itself and the cost of potentially increasing the anti-TNF dose for patients who are otherwise doing well clinically. Regarding the cost of the test itself, it is likely that this will fall as new assays for anti-TNFs are developed. Additionally, it may ultimately be cost-effective to make a small increase in a dose that will prevent flares and possibly hospitalizations and surgeries. Finally, it is likely that TCM will result in significant dose de-escalation of in some patients, and thus at the population level, the dose de-escalations can offset some of the costs of dose escalation. In our cohort, ultimately $15 \%$ of patients either de-escalated or stopped IFX, whereas $27 \%$ of patients de-escalated their IFX dose after the optimization phase in TAXIT. ${ }^{6,7}$

In conclusion, based on the pharmacodynamics and pharmacokinetic principles of anti-TNF drugs, it is expected that patients will have varying serum trough concentrations. TCM of anti-TNFs allows for accurate titration to a target window. Although the exact target for IFX is unknown, the current evidence suggests it is greater than $3 \mu \mathrm{g} / \mathrm{mL}$. We prefer to target concentrations greater than $5 \mu \mathrm{g} / \mathrm{mL}$ to account for variations in a patient's clinical course that can lead to delayed doses or affect drug clearance. We would like to avoid undetectable trough concentrations that may predispose to antibody development and potential loss of response or infusion reactions. Additional studies are needed for other anti-TNFs to define the minimally effective concentration. The principles of TCM can be applied to other 
monoclonal antibodies; however, the therapeutic window may differ. TCM represents a rational dosing strategy based on the pharmacodynamics and pharmacokinetics and is consistent with current published literature that will likely optimize the management of anti-TNF medications in patients with IBD.

\section{REFERENCES}

1. Danese S, Fiorino G, Reinisch W. Review article: causative factors and the clinical management of patients with Crohn's disease who lose response to anti-TNF-alpha therapy. Aliment Pharmacol Ther. 2011;34: $1-10$.

2. Colombel JF, Sandborn WJ, Reinisch W, et al. Infliximab, azathioprine, or combination therapy for Crohn's disease. $N$ Engl J Med. 2010;362: 1383-1395.

3. Imaeda H, Bamba S, Takahashi $\mathrm{K}$, et al. Relationship between serum infliximab trough levels and endoscopic activities in patients with Crohn's disease under scheduled maintenance treatment. J Gastroenterol. 2014;49: 674-682.

4. Karmiris K, Paintaud G, Noman M, et al. Influence of trough serum levels and immunogenicity on long-term outcome of adalimumab therapy in Crohn's disease. Gastroenterology. 2009;137:1628-1640.

5. Afif W, Loftus EV Jr, Faubion WA, et al. Clinical utility of measuring infliximab and human anti-chimeric antibody concentrations in patients with inflammatory bowel disease. Am $J$ Gastroenterol. 2010;105: $1133-1139$.

6. Vande Casteele N, Compernolle G, Ballet V, et al. OP11. Individualized infliximab treatment using therapeutic drug monitoring: a prospective controlled trough level adapted infliximab treatment trial. J Crohns Colitis. 2012;6:S6

7. Vaughn BP, Martinez-Vazquez M, Patwardhan VR, et al. Proactive therapeutic concentration monitoring of infliximab may improve outcomes for patients with inflammatory bowel disease: results from a pilot observational study. Inflamm Bowel Dis. 2014;20:1996-2003.

8. Van Assche G, D'haens G, Noman M, et al. Randomized, double-blind comparison of $4 \mathrm{mg} / \mathrm{kg}$ versus $2 \mathrm{mg} / \mathrm{kg}$ intravenous cyclosporine in severe ulcerative colitis. Gastroenterology. 2003;125:1025-1031.

9. Ziring DA, Wu SS, Mow WS, et al. Oral tacrolimus for steroid-dependent and steroid-resistant ulcerative colitis in children. J Pediatr Gastroenterol Nutr. 2007;45:306-311.

10. Zelenitsky S, Rubinstein E, Ariano R, et al. Vancomycin pharmacodynamics and survival in patients with methicillin-resistant Staphylococcus aureus-associated septic shock. Int J Antimicrob Agents. 2013;41: 255-260.

11. Golan DE, Taskjian AH, Armstrong EJ, et al. Principles of Pharmacology: The Pathophysiologic Basis of Drug Therapy. In: Golan DE, ed. Baltimore, MD: Lippincott Williams \& Wilkins; 2005.

12. Lobo ED, Hansen RJ, Balthasar JP. Antibody pharmacokinetics and pharmacodynamics. J Pharm Sci. 2004;93:2645-2668.

13. Ordas I, Mould DR, Feagan BG, et al. Anti-TNF monoclonal antibodies in inflammatory bowel disease: pharmacokinetics-based dosing paradigms. Clin Pharmacol Ther. 2012;91:635-646.

14. Fasanmade AA, Adedokun OJ, Ford J, et al. Population pharmacokinetic analysis of infliximab in patients with ulcerative colitis. Eur J Clin Pharmacol. 2009;65:1211-1228.

15. Wang W, Wang EQ, Balthasar JP. Monoclonal antibody pharmacokinetics and pharmacodynamics. Clin Pharmacol Ther. 2008;84:548-558.

16. Brambell FW, Hemmings WA, Morris IG. A theoretical model of gammaglobulin catabolism. Nature. 1964;203:1352-1354.

17. Ternant D, Paintaud G. Pharmacokinetics and concentration-effect relationships of therapeutic monoclonal antibodies and fusion proteins. Expert Opin Biol Ther. 2005;5(suppl 1):S37-S47.

18. Schreiber S, Rutgeerts P, Fedorak RN, et al. A randomized, placebocontrolled trial of certolizumab pegol (CDP870) for treatment of Crohn's disease. Gastroenterology. 2005;129:807-818.

19. Schreiber S, Khaliq-Kareemi M, Lawrance IC, et al. Maintenance therapy with certolizumab pegol for Crohn's disease. $N$ Engl J Med. 2007;357: 239-250.

20. Fasanmade AA, Adedokun OJ, Olson A, et al. Serum albumin concentration: a predictive factor of infliximab pharmacokinetics and clinical response in patients with ulcerative colitis. Int $J$ Clin Pharmacol Ther. 2010;48:297-308.

21. Brandse JF, Wildenberg M, de Bruyn J, et al. 157 fecal loss of infliximab as a cause of lack of response in severe inflammatory bowel disease. Gastroenterology. 2013;144:S-36.

22. Moss AC, Brinks V, Carpenter JF. Review article: immunogenicity of anti-TNF biologics in IBD - the role of patient, product and prescriber factors. Aliment Pharmacol Ther. 2013;38:1188-1197.

23. Hwang WY, Foote J. Immunogenicity of engineered antibodies. Methods. 2005;36:3-10.

24. Mohanan D, Slutter B, Henriksen-Lacey M, et al. Administration routes affect the quality of immune responses: a cross-sectional evaluation of particulate antigen-delivery systems. J Control Release. 2010;147: $342-349$.

25. Hanauer SB, Feagan BG, Lichtenstein GR, et al. Maintenance infliximab for Crohn's disease: the ACCENT I randomised trial. Lancet. 2002;359: $1541-1549$.

26. Baert F, Noman M, Vermeire $\mathrm{S}$, et al. Influence of immunogenicity on the long-term efficacy of infliximab in Crohn's disease. $N$ Engl J Med. 2003; 348:601-608.

27. Bartelds GM, Wijbrandts CA, Nurmohamed MT, et al. Anti-adalimumab antibodies in rheumatoid arthritis patients are associated with interleukin10 gene polymorphisms. Arthritis Rheum. 2009;60:2541-2542.

28. Frederiksen MT, Ainsworth MA, Brynskov J, et al. Antibodies against infliximab are associated with de novo development of antibodies to adalimumab and therapeutic failure in infliximab-to-adalimumab switchers with IBD. Inflamm Bowel Dis. 2014;20:1714-1721.

29. Schellekens H. Immunogenicity of therapeutic proteins: clinical implications and future prospects. Clin Ther. 2002;24:1720-1740; discussion 1719.

30. West RL, Zelinkova Z, Wolbink GJ, et al. Immunogenicity negatively influences the outcome of adalimumab treatment in Crohn's disease. Aliment Pharmacol Ther. 2008;28:1122-1126.

31. Sethu S, Govindappa K, Alhaidari M, et al. Immunogenicity to biologics: mechanisms, prediction and reduction. Arch Immunol Ther Exp. 2012;60: 331-344.

32. Radstake TR, Svenson M, Eijsbouts AM, et al. Formation of antibodies against infliximab and adalimumab strongly correlates with functional drug levels and clinical responses in rheumatoid arthritis. Ann Rheum Dis. 2009;68:1739-1745.

33. Nanda KS, Cheifetz AS, Moss AC. Impact of antibodies to infliximab on clinical outcomes and serum infliximab levels in patients with inflammatory bowel disease (IBD): a meta-analysis. Am J Gastroenterol. 2013;108: 40-47; quiz 48

34. Ungar B, Chowers Y, Yavzori M, et al. The temporal evolution of antidrug antibodies in patients with inflammatory bowel disease treated with infliximab. Gut. 2014;63:1258-1264.

35. Vande Casteele N, Gils A, Singh S, et al. Antibody response to infliximab and its impact on pharmacokinetics can be transient. Am J Gastroenterol. 2013;108:962-971.

36. Rosenberg AS. Immunogenicity of biological therapeutics: a hierarchy of concerns. Dev Biol. 2003;112:15-21.

37. Vande Casteele N, Compernolle G, Ballet V, et al. Results on the optimisation phase of the prospective controlled Trough Level Adapted Infliximab Treatment (TAXIT) trial. Gastroenterology. 2012;142:S211-S212.

38. Wang SL, Ohrmund L, Hauenstein S, et al. Development and validation of a homogeneous mobility shift assay for the measurement of infliximab and antibodies-to-infliximab levels in patient serum. $J$ Immunol Methods. 2012;382:177-188.

39. Vande Casteele N, Buurman DJ, Sturkenboom MG, et al. Detection of infliximab levels and anti-infliximab antibodies: a comparison of three different assays. Aliment Pharmacol Ther. 2012;36:765-771.

40. Aarden L, Ruuls SR, Wolbink G. Immunogenicity of anti-tumor necrosis factor antibodies-toward improved methods of anti-antibody measurement. Curr Opin Immunol. 2008;20:431-435.

41. Maser EA, Villela R, Silverberg MS, et al. Association of trough serum infliximab to clinical outcome after scheduled maintenance treatment for Crohn's disease. Clin Gastroenterol Hepatol. 2006;4:1248-1254.

42. Cornillie F, Hanauer SB, Diamond RH, et al. Postinduction serum infliximab trough level and decrease of C-reactive protein level are associated with durable sustained response to infliximab: a retrospective analysis of the ACCENT I trial. Gut. 2014;63:1721-1727. 
43. Bortlik M, Duricova D, Malickova K, et al. Infliximab trough levels may predict sustained response to infliximab in patients with Crohn's disease. J Crohns Colitis. 2013;7:736-743.

44. Lamblin C, Aubourg A, ternant D, et al. P334. Concentration-effect relationship of infliximab in Crohn's disease: results of a cohort study. J Crohns Colitis. 2012;6:S142-S143.

45. Drobne D, Bossuyt P, Breynaert C, et al. Crohn's disease: infliximab trough levels and CRP during infliximab-immunomodulator combination treatment are associated with clinical outcome after immunomodulator withdraw. Gastroenterology. 2011;140:S-62.

46. Arias MT, Vande Casteele N, Drobne D, et al. OP10. Importance of trough levels and antibodies on the long-term efficacy of infliximab therapy in ulcerative colitis. J Crohns Colitis. 2012;6:S5.

47. Seow $\mathrm{CH}$, Newman A, Irwin SP, et al. Trough serum infliximab: a predictive factor of clinical outcome for infliximab treatment in acute ulcerative colitis. Gut. 2010;59:49-54.

48. Yanai H, Hanauer SB. Assessing response and loss of response to biological therapies in IBD. Am J Gastroenterol. 2011;106:685-698.

49. Colombel JF, Sandborn WJ, Allez M, et al. Association between plasma concentrations of certolizumab pegol and endoscopic outcomes of patients with Crohn's disease. Clin Gastroenterol Hepatol. 2014;12:423-431.e1.
50. Roblin X, Marotte H, Rinaudo M, et al. Association between pharmacokinetics of adalimumab and mucosal healing in patients with inflammatory bowel diseases. Clin Gastroenterol Hepatol. 2014;12:80-84.e2.

51. Roblin X, Rinaudo M, Del Tedesco E, et al. Development of an algorithm incorporating pharmacokinetics of adalimumab in inflammatory bowel diseases. Am J Gastroenterol. 2014;109:1250-1256.

52. Velayos FS, Kahn JG, Sandborn WJ, et al. A test-based strategy is more cost effective than empiric dose escalation for patients with Crohn's disease who lose responsiveness to infliximab. Clin Gastroenterol Hepatol. 2013;11:654-666.

53. Steenholdt $\mathrm{C}$, Brynskov J, Thomsen OO, et al. Individualised therapy is more cost-effective than dose intensification in patients with Crohn's disease who lose response to anti-TNF treatment: a randomised, controlled trial. Gut. 2014;63:919-927.

54. Panaccione R, Ghosh S, Middleton S, et al. Combination therapy with infliximab and azathioprine is superior to monotherapy with either agent in ulcerative colitis. Gastroenterology. 2014;146:392400.e3.

55. van Schaik T, Maljaars JP, Roopram RK, et al. Influence of combination therapy with immune modulators on anti-TNF trough levels and antibodies in patients with IBD. Inflamm Bowel Dis. 2014;20:2292-2298. 